\title{
Electrochemical Polymerization of Furfural on a Platinum Electrode in Aqueous Solutions of Potassium Biphthalate
}

\author{
Jorge Luiz Joaquim Hallal, Alzira Maria Serpa Lucho, Reinaldo Simões Gonçalves* \\ Institute of Chemistry, Federal University of Rio Grande do Sul \\ C. P. 15049, 91501-970 Porto Alegre - RS, Brazil
}

Received: March 18, 2003; Revised: November 20, 2004

\begin{abstract}
Three different electrochemical methods confirm the growth processes of polyfurfural on platinum electrodes in aqueous solutions. The electrochemical oxidative polymerization of furfural occurs only with $0.10 \mathrm{~mol} \mathrm{~L}^{-1}$ potassium biphthalate as the supporting electrolyte. Electrochemical and spectroscopic methods are employed to characterize the polymeric film produced. Based on spectroscopic data, a polymeric structure involving furfural and biphthalate anions is discussed.
\end{abstract}

Keywords: furfural, polyfurfural, platinum, aqueous potassium biphthalate solutions

\section{Introduction}

Conducting polymers are regarded as potential materials for the electronic industry. The possibility of combining the properties of organic polymers and the electronic properties of semiconductors in these new materials has been the driving force for various applications. Conducting polymers can be prepared via chemical ${ }^{1-3}$ or electrochemical polymerization ${ }^{4}$. Electronically conducting polymer films generated by electrochemical polymerization are usually deposited onto a supporting electrode surface by various electrochemical techniques, including potentiostatic (constant-potential), galvanostatic (constant current) and potentiodynamic (cyclic voltammetry) methods. Conjugated polymers have attracted considerable scientific interest for their potential use due to their unusual electrical, electrochemical and optical properties ${ }^{5}$. A new generation of electroactive polymers based on polyheterocycles (polypyrrole, polythiophene) has been the object of investigation ${ }^{6-10}$. Attention so far has focused primarily on the chemical polymerization of conjugated polymers bearing furan rings, while little attention has been dedicated to their electrochemical polymerization ${ }^{11-13}$. This paper deals with a potential candidate for new applications developed from laboratory studies based on furfural (2-furancarboxyaldehyde). Furfural is produced from many sources because most agricultural wastes and woods contain sufficient quantities of pentosans, thus justifying this research. The worldwide production of furfural in 1985 was about 200,000 tons, originating mostly from corncobs, cottonseed, rice hulls, sugarcane bagasse, wood, and involved various wood technologies and organic solvent plants ${ }^{14}$. Despite the poor chemical stability of furfural (2-furancarboxaldehyde), the literature contains evidence confirming the electroactivity of this compound in different electrodes ${ }^{15-16}$. However, much less attention has so far focused on the electropolymerization of polyfurans ${ }^{17}$, probably because of their supposedly less well-defined structures and poor stability. Furfuryl alcohol polymerization is a well known homogeneous acid catalysis process ${ }^{2}$. Furfural, which has been characterized as an electrophore, can be reduced into furfuryl alcohol or oxidized into furoic acid ${ }^{15}$. The main purpose of this study is directed to obtain a stable polymeric film from electrooxidation of furfural in order to offer a organic barrier against corrosion processes. The next step should apply these procedures on non-noble metallic surfaces such as steel, zinc and others metals.
In a previous investigation in our laboratory, the presence of an organic polyfurfural film was proposed to explain the changes in the electrochemical behavior of a platinum platinized electrode ${ }^{16}$. Current versus potential curves and electrochemical impedance measurements conclusively characterized the presence of the organic film on the electrode surface. The polymer film was electrogrown by keeping the current density constant at $34 \mu \mathrm{A} \mathrm{cm}^{-2}$ (galvanostatic method) and applying a constant potential of around $0.30 \mathrm{~V}$ (SCE) for varying periods of time (potentiostatic method) in acetonitrile.

The present work describes the electrochemical polymerization of furfural in an aqueous solution formed on platinum by three distinct electrochemical methods.

The film was characterized by scanning electron microscopy (SEM), differential scanning calorimetry (DSC) and UV spectroscopy. Electrochemical experiments were also conducted to confirm the presence of the organic film on the electrode surface. This verification was essentially based on cyclic voltammetry.

\section{Experimental}

\subsection{Reagents and materials}

Pure furfural was obtained from Merck; however, periodical distillation was required before use to maintain its level of purity. An aqueous solution containing $80.0 \mathrm{mmol} \mathrm{L}^{-1}$ of furfural was prepared by dissolving this compound with pure conductive water. Potassium biphthalate (p.a.) from Merck was used as the supporting electrolyte. Only $0.10 \mathrm{~mol} \mathrm{~L}^{-1}$ supporting electrolyte aqueous solutions were tested.

\subsection{Cell and electrode materials}

Electrochemical polymerization was carried out in a conventional three-electrode electrochemical cell. The working electrodes with distinct active surfaces were made of pure platinum wire and the auxiliary electrode also consisted of a platinum wire, while the reference was a saturated calomel electrode. The working electrodes were subjected to conventional polishing with alumina (50-200 micron), degreased with acetone and dried with hot air, prior to the electropolymerization step, thus avoiding contamination and superficial irregularities. 


\subsection{Techniques and instrumentation}

The polymers were electrosynthesized using a TECTROL model TCH1000-005 dc power source to grow the film galvanostatically and an AUTOLAB PGSTAT 30 potentiostat/galvanostat for potentiostatic and potential cycling film electrogrowth. Micrographs of the electrodes were taken using a JSM model 5800 microscope. A Perkin-Elmer DSC-4 calorimeter was employed for the differential scanning calorimetry experiments. UV studies were made using a Shimadzu UV-VIS model 1601 PC spectrophotometer.

\section{Results and Discussion}

\subsection{Electrochemical characterization of the organic film formed on the electrode surface}

\subsubsection{Galvanostatic experiments}

In this study, the polymer film was grown anodically by passing $10 \mathrm{~mA}$ of current through the working electrode immersed in an aqueous solution of $0.10 \mathrm{~mol} \mathrm{~L}^{-1}$ potassium biphthalate containing $80 \mathrm{mmol} \mathrm{L}^{-1}$ of furfural. Various polarization times were tested. Although the presence of the film on the electrode surface became visible after 30 minutes of polarization, the electrode surface was totally covered only after 90 minutes of polarization, as shown in Figure 1. This image, taken with a microscope and magnified 64 times, shows the electrode covered only partially by the polymer film. A point worth noting is that, by this method, the film grew continuously throughout the polarization time, suggesting that it may have conducted the electricity since the process was not interrupted after the first layer of the organic polymer was formed. This may be considered the first piece of evidence that the film should support the charge transfer process on the polymeric structure. The film's morphology and the influence of the polarization time on the structure of the film formed on the electrode surface will be discussed below.

Despite the visible modification of the electrode surface, confirmation of the presence of the film was obtained by comparing the resulting voltammetric profile when the modified electrode was transferred to an aqueous solution of $0.10 \mathrm{~mol} \mathrm{~L}^{-1}$ potassium biphthalate without furfural. The $\mathrm{I}(\mathrm{E})$ profiles of the electrode without the presence of the film, which were recorded at $0.10 \mathrm{Vs}^{-1}$ in the potential range of $1.00 \mathrm{~V}(\mathrm{SCE})$ to $1.75 \mathrm{~V}(\mathrm{SCE})$, clearly show electrooxidation of the electrode surface in this interval. A simple strategy was employed to confirm the presence of the film formed on the electrode surface as a function of the electrolysis time. Figure 2 shows the charge associated with this electrooxidation process $(\mathrm{Qb})$. A comparison of the $\mathrm{I}(\mathrm{E})$ profiles of both modified and platinum electrodes indicates that this charge decreases. This effect is dependent on the polarization time, suggesting that the film thickness increases proportionally. The coverage of the electrode $(\theta)$ was calculated from the charges using the following equation:

$$
\theta=\frac{Q_{b}-Q_{m e}}{Q_{b}}
$$

where $Q_{b}$ is the charge associated with the electrooxidation process of the unaltered electrode, and $Q_{m e}$ is the charge associated with the electrooxidation process of the electrode modified by the film formed during different polarization times.

Figure 3 shows the effect of the coverage of the electrode surface as function of the polarization times on the electrooxidation process of the metal. As expected, the coverage of the electrode surface increases along with the polarization time. The electrode surface was saturated after 60 minutes of polarization.
In addition to this evidence, another unequivocal strategy was applied to confirm the modification of the electrode's electrochemical behavior as a function of the presence of the polymeric film. The electrode was transferred to another cell containing $0.10 \mathrm{~mol} \mathrm{~L}^{-1}$ of aqueous sulfuric acid. Voltammograms of platinum electrodes in this medium are well defined in the literature ${ }^{18}$. The changes in the $\mathrm{I}(\mathrm{E})$ profiles revealed through a comparison of the two electrodes may be attributed to the presence of the film.

The data obtained from the galvanostatic experiments were characterized by comparing the $\mathrm{I}(\mathrm{E})$ curves of the platinum electrode in aqueous sulfuric acid solutions with and without the film on the electrode surface. Figure 4 clearly shows how the organic film influ-

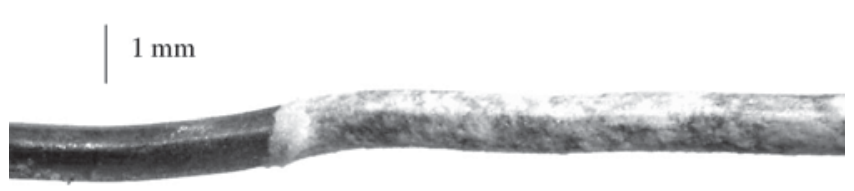

Figure 1. Image of the platinum electrode surface covered with the organic film after 90 minutes of anodic growth with the application of $10 \mathrm{~mA}$ of current, taken with a digital camera with zoom.

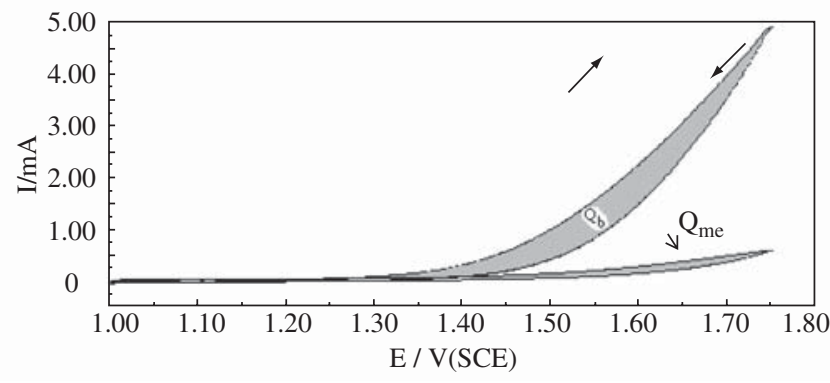

Figure 2. Cyclic voltammograms of the platinum electrode recorded in an aqueous aerated solution of $0.10 \mathrm{~mol} \mathrm{~L}^{-1}$ potassium biphthalate, recorded at $\mathrm{v}=0.10 \mathrm{Vs}^{-1}$; modified by the presence of polymer on the electrode surface, and without the film.

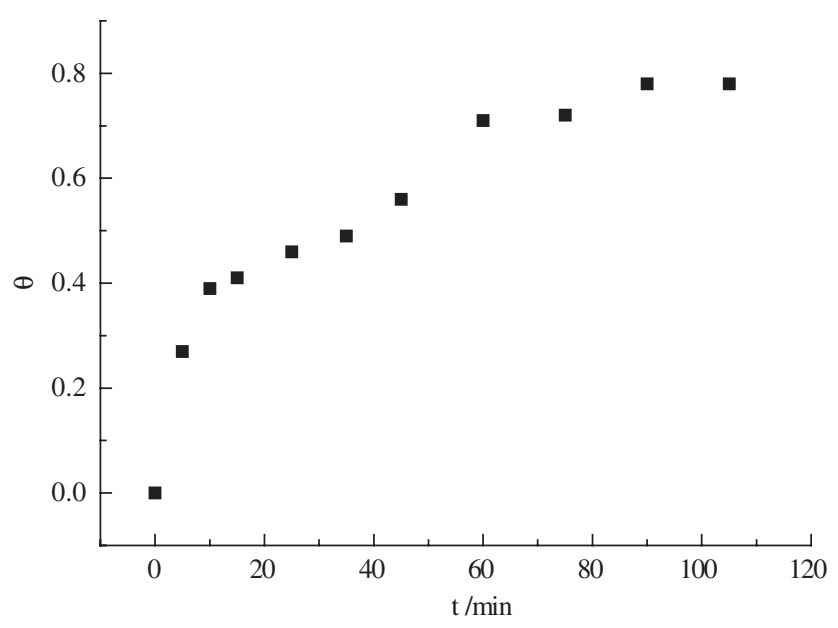

Figure 3. Effect of polarization time in the galvanostatic experiments on the degree of coverage $(\theta)$ of the electrode surface, measured during the electrooxidation of the platinum electrode in aqueous aerated solution of $0.10 \mathrm{~mol} \mathrm{~L}^{-1}$ potassium biphthalate and recorded at $\mathrm{v}=0.10 \mathrm{Vs}^{-1}$. 
ences the electrochemical behavior of the platinum electrode in an appropriate potential window. The choice of potential range served to confirm how the charge transfer processes can be affected in the shift from a double layer formation $(0.0 \mathrm{~V} / \mathrm{SCE})$ to a platinum oxide formation (1.2 V/SCE). The anodic currents relating to the platinum electrode's electrooxidation process were shown to decrease in a comparison of the two electrodes. On the other hand, the currents observed during the cathodic potential sweep relating to the electroreduction of the platinum oxide practically disappeared. A possible explanation of this effect is that, after 90 minutes of polarization, the electrode was almost totally covered by the organic film, which effectively prevented the formation of platinum oxide.

The current of the modified electrode decreased in the more negative potential range in which cathodic currents relating to hydrogen adsorption/desorption processes prevailed. Both the anodic and the cathodic processes on the platinum surface in aqueous sulfuric acid solutions were clearly altered by the presence of the film on the electrode surface. It is important to point out the film's electrical conductivity, which was evidenced by the noninterruption of the charge transfer processes on the electrode surface as the polymer was formed.

\subsubsection{Potentiostatic experiments}

In this experiment, the potential of the working electrode was kept constant at $2.65 \mathrm{~V}(\mathrm{SCE})$ during various polarization times. The organic film grew from the same solution tested before. Deaerated solutions were tested to prevent parallel reactions on the electrode surface. The same strategy was applied to confirm the presence of the film on the electrode surface. The resulting voltammetric profile when the modified electrode was transferred to an aqueous solution of $0.10 \mathrm{~mol} \mathrm{~L}^{-1}$ potassium biphthalate without furfural was used for this purpose. Figure 5 shows the degree of coverage of the surface at different polarization times. The same conclusions can be drawn by analyzing the data showed in this figure, i.e., coverage of the electrode surface increased with polarization time.

However, the main evidence of the electrochemical oxidation of furfural on the electrode surface, which resulted in visible coverage, is shown in Figure 6. The current versus time curves obtained when the electrode was polarized at $2.65 \mathrm{~V}(\mathrm{SCE})$ in the absence and in the presence of furfural are depicted. A comparison of the current

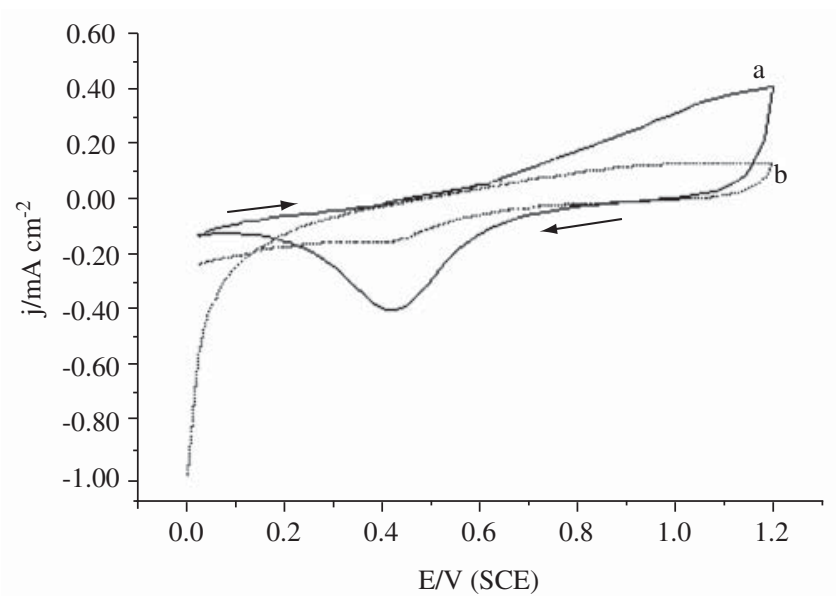

Figure 4. Voltamogramms of platinum electrode at $25^{\circ} \mathrm{C}$ in aqueous aerated solution of $0.50 \mathrm{~mol} \mathrm{~L}^{-1} \mathrm{H} 2 \mathrm{SO} 4$, recorded at $\mathrm{v}=0.10 \mathrm{Vs}^{-1}$ : a) bare electrode, and b) after galvanostatic electrogrowth of polyfurfural, applying $10 \mathrm{~mA}$ of current for 90 minutes in $0.10 \mathrm{~mol} \mathrm{~L}^{-1}$ of potassium biphthalate and $80 \mathrm{mmol} \mathrm{L}^{-1}$ of furfural. densities in the presence and in the absence of furfural reveals an unequivocal increase in the current density of the electrode with this organic compound. The anodic current was likely related with the electrooxidation process of furfural (1), giving the furfural dication (2), according to the Scheme 1.

The onset of polymer growth was likely related with the formation of furfural dication (2). The stability of the dication using both positions 2 and 5 on the furan ring was theoretically determined ${ }^{19}$ and the same mechanism was proposed to explain the polymer formed from furfuryl alcohol ${ }^{20}$.<smiles>O=C(O)c1ccco1</smiles>

(1)

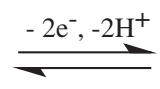

Scheme 1

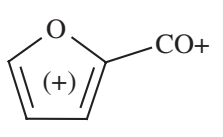

(2)

\section{Schene 1}

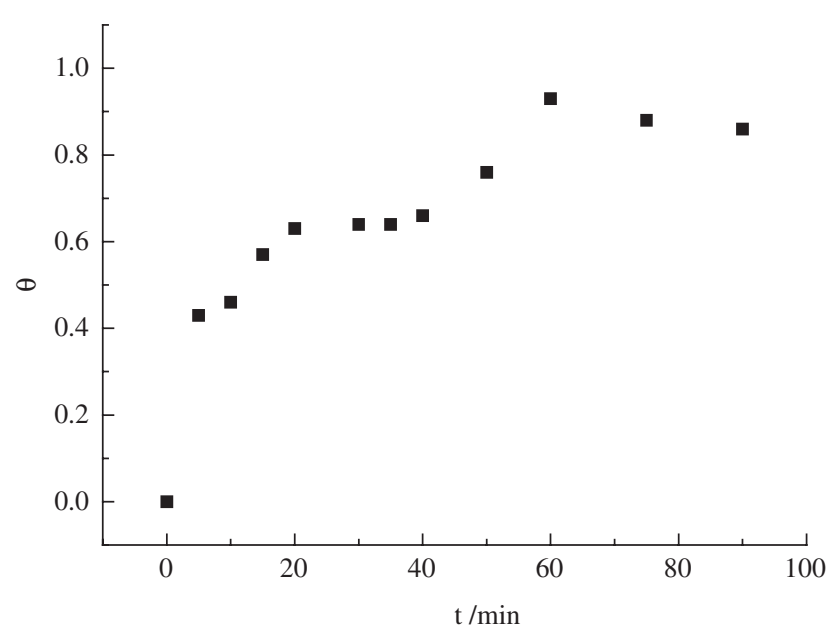

Figure 5. Effect of the polarization time in the potentiostatic experiments on the degree of coverage $(\theta)$ of the electrode surface, measured during the electrooxidation of the platinum electrode in an aqueous aerated $0.10 \mathrm{~mol} \mathrm{~L}^{-1}$ potassium biphthalate solution and recorded at $\mathrm{v}=0.10 \mathrm{Vs}^{-1}$.

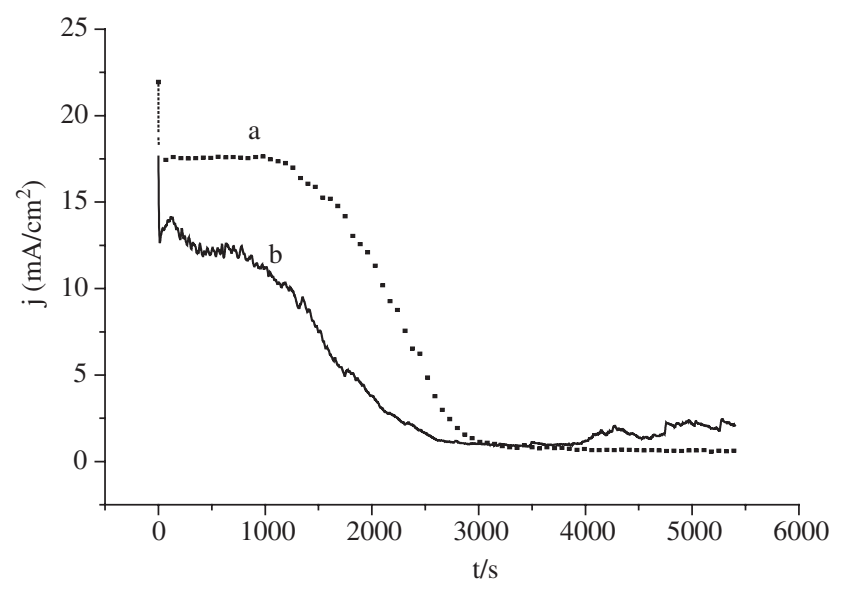

Figure 6. Current versus time curves of potentiostatic experiments at $2.65 \mathrm{~V}$ (SCE) for 90 minutes in deaerated solutions: a) $0.10 \mathrm{~mol} \mathrm{~L}^{-1}$ potassium biphthalate in the presence of $80 \mathrm{mmol} \mathrm{L}^{-1}$ furfural; b) $0.10 \mathrm{~mol} \mathrm{~L}^{-1}$ potassium biphthalate. 


\subsubsection{Potentiodynamic experiments}

Potentiodynamic experiments were also carried out in this medium to check the possibility of the anodic polymerization of furfural in the potential range of $2.00 \mathrm{~V}$ to $2.65 \mathrm{~V}$ (SCE) at $50 \mathrm{mV} \mathrm{s}^{-1}$. The film grew after 400 cycles. When the number of cycles increased, a spongy white film appeared on the electrode surface. The same approach was applied to characterize the presence of the organic film formed on the electrode surface. The resulting voltammetric profiles when the modified electrode was transferred to an aqueous solution of $0.10 \mathrm{~mol} \mathrm{~L}^{-1}$ potassium biphthalate without the presence of furfural were used for this purpose. Figure 7 shows the degree of surface coverage in different sweep cycles. The same conclusions can be drawn by analyzing the curve shown in this figure, i.e., coverage of the electrode surface increased with the number of cycles.

The same strategy was applied before transferring the electrode modified by the film to another electrochemical cell containing aqueous sulfuric acid solution. Figure 8 shows the voltammograms of the modified electrode in deaerated $0.50 \mathrm{~mol} \mathrm{~L}^{-1}$ sulfuric acid solution, as well as the $\mathrm{I}(\mathrm{E})$ curve of the bare electrode. The anodic current increased during the anodic potential sweep. The same effect was observed during the cathodic potential sweep when comparing the cathodic peak with the bare electrode. Both oxidation/reduction electrochemical processes apparently increased in response to the enhancement of the electrode's active surface. These contributions may be associated with the redox charge-discharge processes of the polyfurfural, as well as the formation of a $\mathrm{PtO}$ monolayer and the oxidation of the film.

\subsubsection{Comparison among the three electrochemical} methods of growing

The structure of the film obtained by the galvanostatic method as well as the polymer's adherence was dependent on the polymerization time and current applied. The current was controlled by the equipment; however, the electrode potential was shifted without control to more positive potential value. This variable should affect the crystalline structure of the polymer as well as the roughness. Studies involving others electrochemical methods the electrode potential was kept under control. The selected values were not so positive, inducing a polymeric structure with a granular morphology. The galvanostatic electrogrow should be suitable if the adherence of the film on the electrode surface is used as a criterion to choice between the three methods.

\subsubsection{Surface morphology of the film}

Having clearly characterized the presence of the organic film by the electrochemical methods approach, the next step was to determine the morphology and structure of the newly formed polymer.

The surface morphology of the organic film was studied by SEM photomicrographs. Figure 9 shows the SEM photomicrographs of the electrodes after the polyfurfural film was grown using three electrochemical techniques. A surface examination revealed considerable differences in the film morphology according to the electrochemical synthesis method employed. The coatings on the electrode surface formed by the potentiodynamic and potentiostatic methods showed a granular morphology. The film showed little adherence when few cycles or short polarization times were applied. On the other hand, the structure of the film obtained by the galvanostatic method and the polymer's adherence were also dependent on the polymerization time and current applied. Fast film growth led to poor adherence of the polymer on the substrate, while longer polymerization times resulted in more adherent films with a more compact structure and higher roughness. An analysis of the film synthesized during short polymerization times revealed a laminar structure. It is a well known fact that compact layers are resistant to degradation while laminar structures hydrolyze more easily ${ }^{21}$. Figure 10 shows how the polarization time affects the morphology of the film formed on the electrode surface produced by the galvanostatic method.

A laminar structure is visible with short polarization times, while 90 minutes of galvanostatic electrogrowth lead to a more compact morphology.

\subsubsection{UV spectroscopic studies}

To confirm the presence of furfural in the polymer structure, several spectroscopic measurements were taken in solutions containing different furfural concentrations in the 200 to $350 \mathrm{~nm}$ wavelength, as shown in Figure 11. The UV spectra of the samples were linear at $270 \mathrm{~nm}$, where the maximum absorption occurs, in the furfural concentration range of $2.0 \times 10^{-5} \mathrm{~mol} \mathrm{~L}^{-1}$ to $8.0 \times 10^{-5} \mathrm{~mol} \mathrm{~L}^{-1}$. The quantity of furfural consumed during the galvanostatic experiment

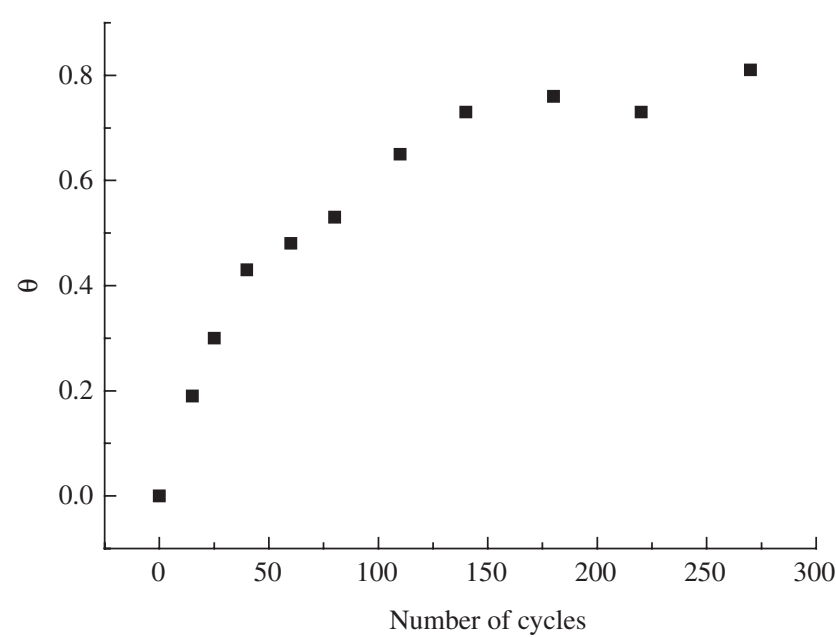

Figure 7. Effect of the number of cycles during $\mathrm{CV}$ experiments on the degree of coverage $(\theta)$ of the electrode surface, measured during the electrooxidation of the platinum electrode in an aqueous aerated solution of $0.10 \mathrm{~mol} \mathrm{~L}^{-1}$ potassium biphthalate and recorded at $\mathrm{v}=0.10 \mathrm{Vs}^{-1}$.

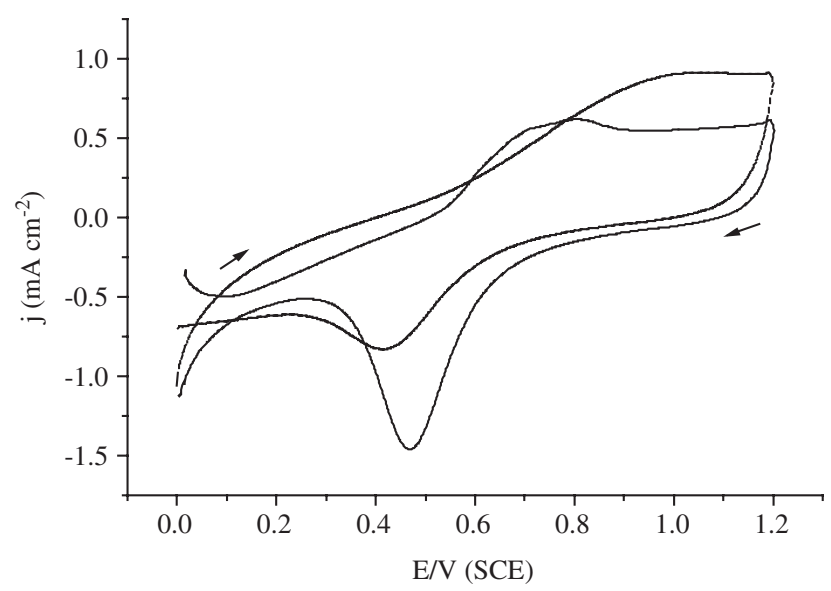

Figure 8. Voltamogramms of platinum electrode at $25^{\circ} \mathrm{C}$ in an aqueous aerated solution of $0.50 \mathrm{~mol} \mathrm{~L}^{-1} \mathrm{H} 2 \mathrm{SO} 4$ recorded at $\mathrm{v}=0.10 \mathrm{Vs}^{-1}$ : a) bare electrode; b) after potentiodynamic electrogrowth of polyfurfural during 400 cycles in the potential range of $2.00 \mathrm{~V}$ to $2.65 \mathrm{~V}(\mathrm{SCE})$ at $50 \mathrm{mV} / \mathrm{s}$. 


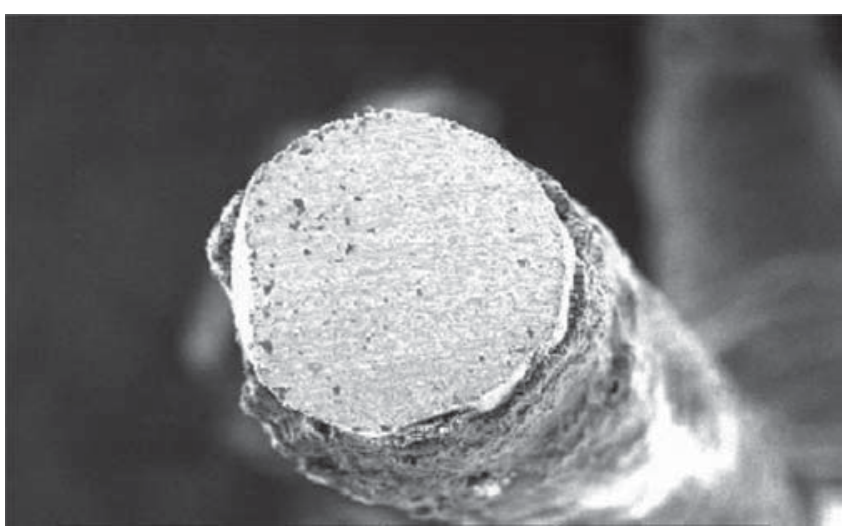

(a)

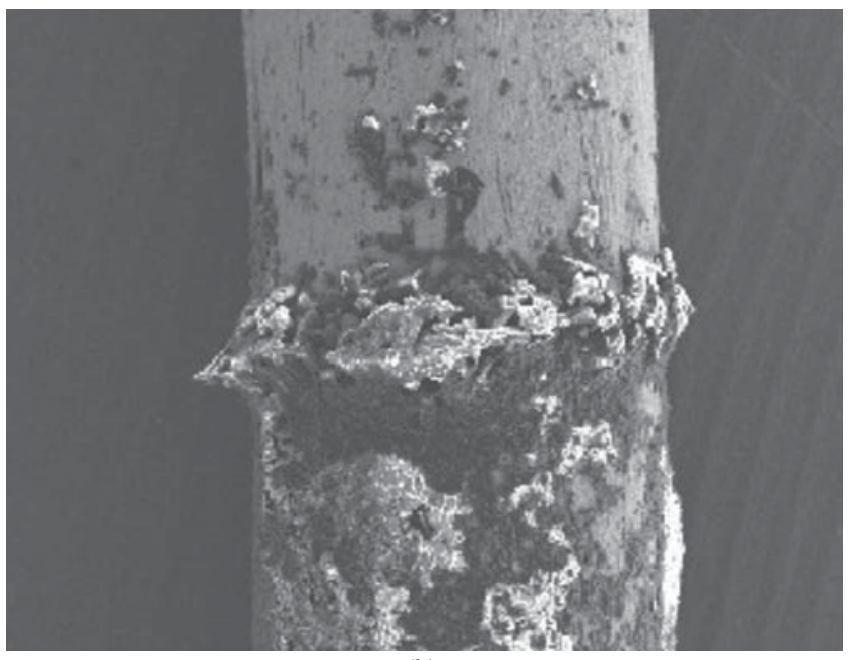

(b)

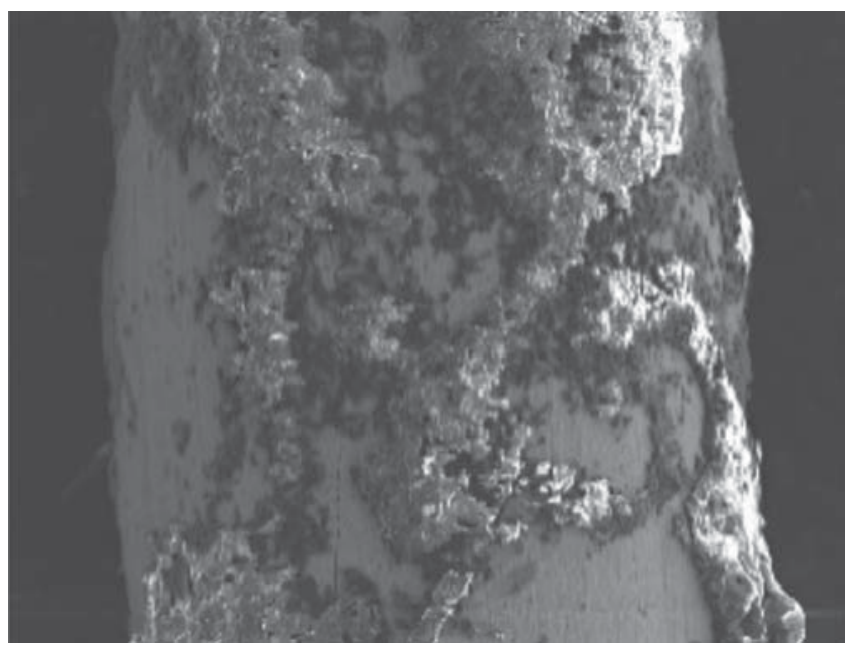

(c)

Figure 9. SEM photomicrographs showing the presence of the film formed on the electrode surface by three different electrochemical techniques: a) galvanostatic; b) potentiodynamic; c) potentiostatic.

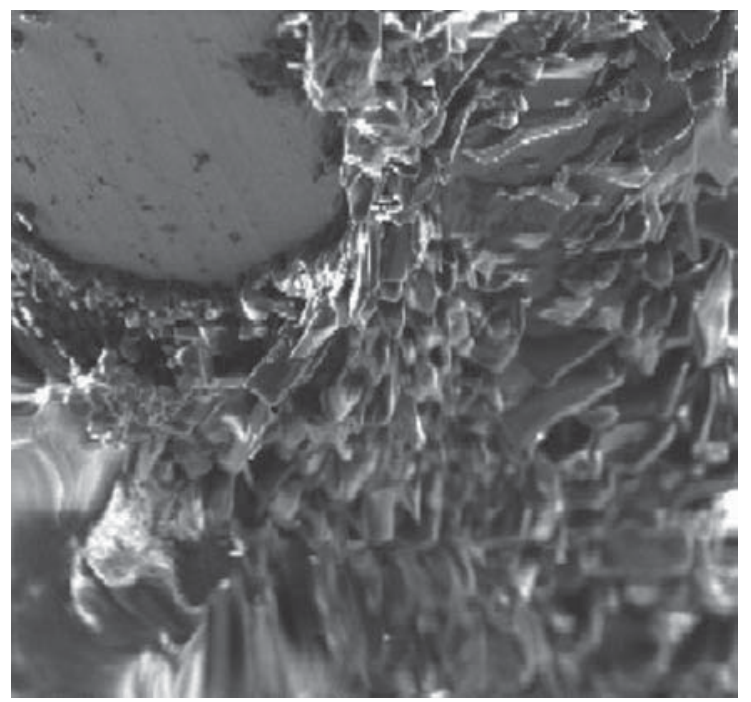

(a)

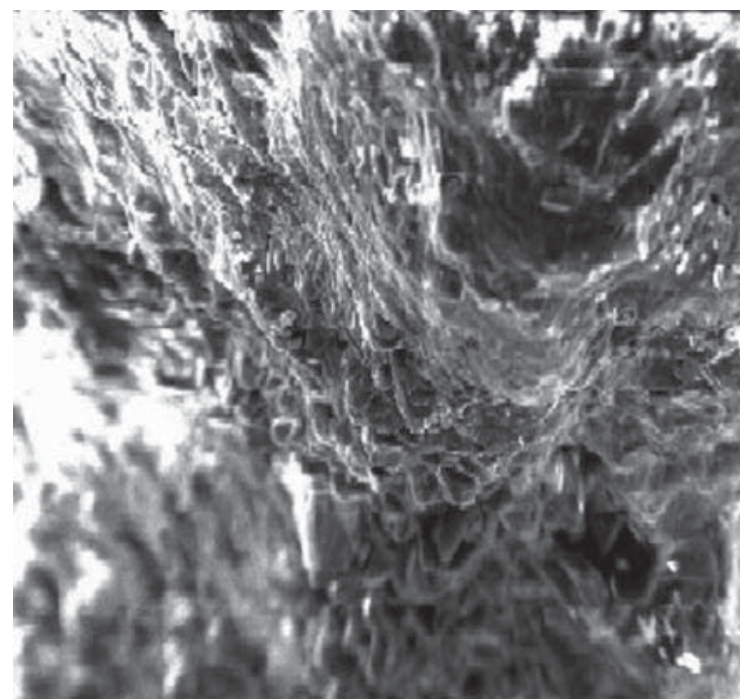

(b)

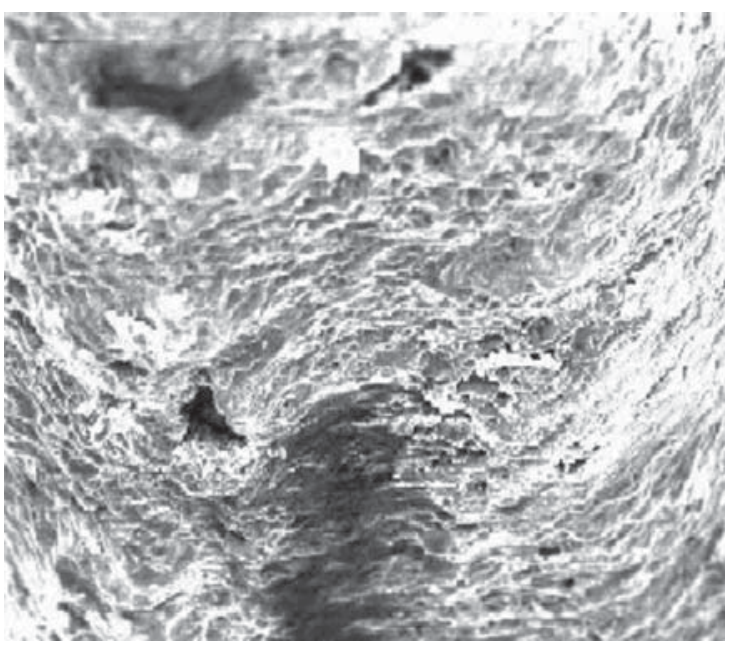

(c)

Figure 10. SEM photomicrographs of the modified electrode after galvanostatic electrogrowth, applying $10 \mathrm{~mA}$ of current in $0.10 \mathrm{~mol} \mathrm{~L}^{-1}$ of aerated potassium biphthalate and $80 \mathrm{mmol} \mathrm{L}^{-1}$ of furfural for, a) 30 minutes; b) 60 minutes; c) 90 minutes. 
was calculated based on this behavior, with the working electrode exposed to an anodic current of $10 \mathrm{~mA}$ for 90 minutes. The presence of the film on the electrode surface was clearly visible after this time. The electrolytic solutions were analyzed in this wavelength. The difference in light absorption between furfural solutions before and after the electrolysis revealed that $2.80 \times 10^{-4}$ moles of furfural were consumed; indicating that $2.69 \times 10^{-2} \mathrm{~g}$ of furfural was oxidized during this experiment. The fact that a certain amount of furfural was consumed may be considered an indication that the compound participated effectively in the polymer's composition.

This hypothesis was confirmed by a calculation of the theoretical furfural mass that should be consumed when this current is applied for that period of time, assuming a charge transfer process involving $2 \mathrm{~F}$ $\mathrm{mol}^{-1}$ of furfural, as proposed in Scheme 1. The value calculated theoretically is $2.68 \times 10^{-2} \mathrm{~g}$, which is very close to that determined from spectroscopic studies of the electrolytic solution. The coincidence of the numbers allows one to conclude that furfural effectively participated in the polymer structure. The UV spectroscopy of the film dissolved in absolute ethanol was conclusive with regard to the presence of furfural in the polymer structure, since a clearly identifiable peak at $270 \mathrm{~nm}$ was observed, as depicted in Figure 12.

Finally, the polymer formed on the electrode surface was studied in order to confirm the presence of furfural in the film structure. The organic film on the electrode surface was scratched and examined, based on an approach whereby, using Differential Scanning Calorimetry (DSC) and UV spectroscopic techniques, correlations can be identified in the film's chemical structure.

\subsubsection{Differential scanning calorimetry}

Figure 13 shows the first scan of the resins obtained from the galvanostatic electrogrowth of furfural according to the above described procedure. The highest temperature at which the polymer melting process occurred was found to be $202.01{ }^{\circ} \mathrm{C}$, which far exceeds the boiling point of pure furfural $\left(161.7^{\circ} \mathrm{C}\right)$ and which can therefore not be associated with potassium biphthalate, since this compound decomposes before melting. These findings indicate that the polymer structure involved a furfural and potassium biphthalatebased resin. The second scan confirmed that the initial structure of the compound was destroyed, since the melting point was that of phthalate anhydride.

The electrochemical resinification of furfural is a more complex process than that proposed for chemically generated furfuraldehyde resins $^{21}$. The structure of the polymer should agree with the one proposed for cationic polymerization, involving an initiation and propagation mechanism ${ }^{22}$. However, the spectroscopic data and other information suggest the mechanism presented in Scheme 2.

\section{Conclusions}

This paper demonstrated that a polymeric furfural film was formed on a platinum surface in aqueous potassium biphthalate solutions. The process occurred by electrochemical oxidation of furfural under current or potential control. The film's adherence, thickness and morphology proved to be dependent on polarization time. A complex polymeric structure involving the polyfurfural film and biphthalate anions was favored due to the greater availability of anions.

\section{Acknowledgements}

The authors wish to thank FAPERGS and CEFET-Pelotas(RS) for their financial support of this work. We are also indebted to C. L. Petzhold for his helpful suggestions regarding the NMR spectroscopy and DSC experiments, to C. C. Moro for the UV spectroscopy and to G. E. Englert for the SEM photomicrographs.

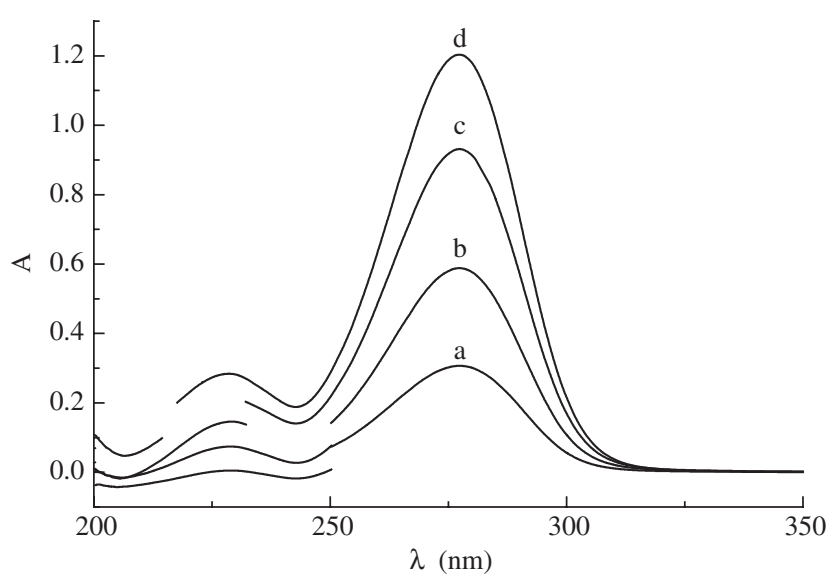

Figure 11. UV spectra of the aqueous solutions containing different furfural concentrations: a) $2.0 \times 10^{-5} \mathrm{~mol} \mathrm{~L}^{-1}$; b) $4.0 \times 10^{-5} \mathrm{~mol} \mathrm{~L}^{-1}$; c) $6.0 \times 10^{-5} \mathrm{~mol} \mathrm{~L}^{-1}$; d) $8.0 \times 10^{-5} \mathrm{~mol} \mathrm{~L}^{-1}$.

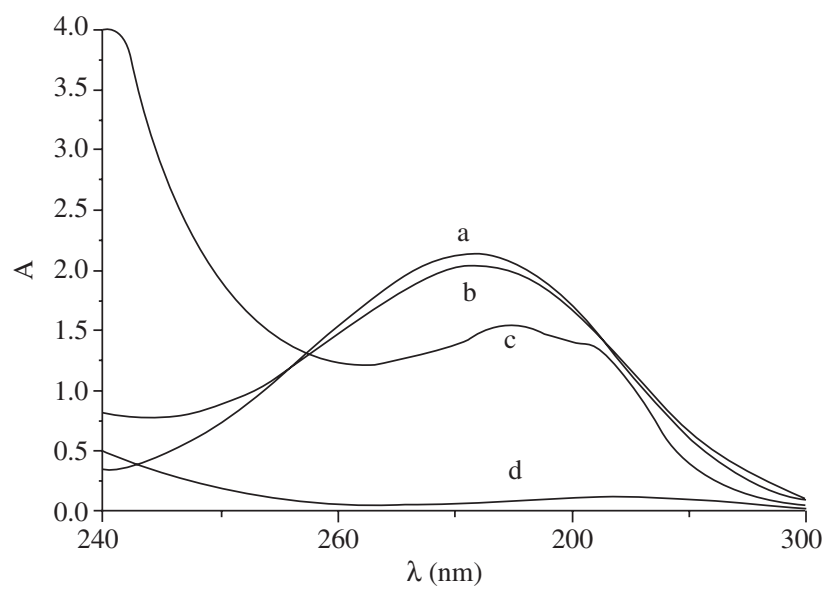

Figure 12. UV spectra of the ethanolic solutions containing, a) furfural; b) furfural and potassium biphthalate; c) polymer solution; d) potassium biphthalate.

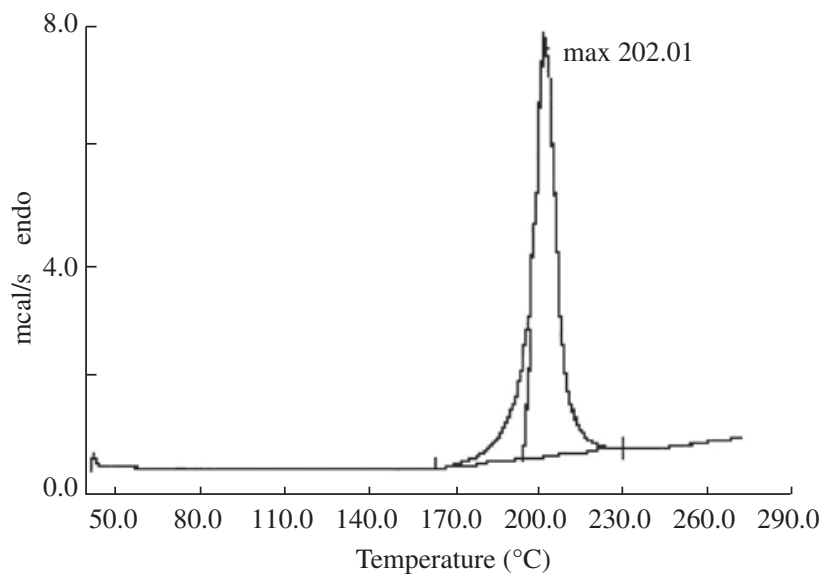

Figure 13. DSC curve of the resin obtained after galvanostatic electrogrowth applying $10 \mathrm{~mA}$ of current for 90 minutes. 
a)<smiles>O=C(O)c1ccco1</smiles><smiles>O=C(O)c1ccco1</smiles>

b)<smiles>O=C(O)c1ccco1</smiles><smiles>C#Cc1ccco1</smiles>

c)<smiles>O=Cc1ccco1</smiles>
2<smiles>O=C(O)c1ccccc1C(=O)O</smiles>

d)<smiles>COC(=O)c1ccccc1C(=O)OC(=O)c1ccc(OC(=O)c2ccccc2C(=O)OC)o1</smiles>

Scheme 2

\section{References}

1. Gonzalez R, Rieumont J, Figueroa JM, Siller J, Gonzalez H. Kinetics of furfuryl alcohol polymerization by iodine in methylene dichloride. Eur Polym J. 2002; 38:281-286.

2. Batista PS, Souza MF. Furfuryl alcohol conjugated oligomer pellicle formation. Polymer. 2000; 41:8263-8269.

3. Gonzalez E, Gonzalez M, Gonzalez R, Ortiz P, Rieumont J. The resinification of 2-ethenylfuran catalyzed by trifluroacetic acid in water-chloroform mixtures. Polymer. 2000; 41:2491-2498.

4. Sadki S, Schottland P, Brodie N, Sabouroud G. The mechanisms of pyrrole electropolymerization. Chem Soc Rev. 2000; 29:283-293.

5. Siminionescu CI, Cianga I, Ivanoiu M, Duca Al, Cocarla I. Synthesis and electrochemical polymerization of some monomers with Schiff base or vinylene structures and thiophene moieties. Eur Pol J. 1999; 35:587-599.

6. Zotti G, Schiavon G, Berlin A, Pagani G. The role of water in the

electrochemical polymerization of pyrroles. Electrochim Acta. 1989; 34(6):881-884.

7. Curran D, Grimshaw J, Perera D. Poly(pyrrole) as a support for electrocatalytic materials. Chem Soc Rev. 1991; 20:391-404.

8. Aeiyach S, Bazzaoui EA, Lacaze P-C. Electropolymerization of thiophene on oxidizable metals in organic media. J Electroanal Chem. 1997; 434:153-162.

9. Schrebler R, Grez P, Cury P, Veas C, Merino M, Gómez H, et al. Nucleation and growth mechanisms of poly(thiophene) Part 1. Effect of electrolyte and monomer concentration in dichloromethane. J Electroanal Chem. 1997; 430:77-90.

10. Okuzaki H, Kondo T, Kunugi T. Characteristics of water in polypyrrole films. Polymer. 1999; 40:995-1000.

11. Lamb BS, Kovacic PJ. Polymerization of Aromatic Nuclei. XXIV. Investigation of oligomer and polymer from furan and trichloroacetic acid. Polymer Sci. 1980; 18:2423-2436.

12. Buchwalter SL. The polymerization of furfuryl acetate in acetonitrile. J Polymer Sci. 1985; 23:2897-2911.

13. Gonçalves RS, Olivera WX. Electrochemical evidences of the protection efficiency of furfural on the corrosion processes of low carbon steel in ethanolic médium. J Braz, Chem Soc. 1992; 3(3):92-94.

14. Encyclopedia of Polymer Science and Engineering. Furan polymers. $1987 ; 7: 454-473$.

15. Chamoulaud G, Floner D, Moinet C, Lamy C, Belgsir EM. Biomass convertion II: simultaneous electrosyntheses of furoic acid and Furfuryl alcohol on modified graphite felt electrodes. Electrochim Acta. 2001; 46:2757-2760.

16. Gonçalves RS, Azambuja DS, Lucho AMS. Evidências eletroquímicas da formação do filme de polifurfural sobre platina platinizada em acetonitrila. Proceedings of the XII Simpósio Brasileiro de Eletroquímica e Eletroanalítica; 2001 Apr 22-26; Gramado-RS; Brasil. 2001. p. 46-48.

17. Tediar F. Électropolymérisation du furanne-1 Obtention des produits sur différents substrats. Eur Polym J. 1985; 21(3):317-319.

18. Bard AJ, Faulkner LR, Electrochemical Methods - Fundamentals and Applications, Toronto: John Wiley \& Sons; 1980. p. 540.

19. González R, Martínez R, Ortiz P. Polymerization of furfuryl alcohol with trifluoroacetic acid: the influence of experimental conditions. Makromol Chem. 1992; 193:1-9.

20. Nunziante P, Pistoia G. Factors affecting the growth of thick polyaniline films by cyclic voltammetry technique. Electrochim Acta. 1989; 34(2):223-228.

21. Sánchez R, Hernández C, Keresztury G. Structural analysis of acid catalyzed furfuraldehyde resins by thermal degradation techniques. Eur Polym J. 1994; 30(1):43-50.

22. Ledwith A, Sherrington DC. Reactivity and mechanism in cationic polymerization. In: Jenkins AD, Ledwith A, editors. Reactivity, Mechanism and Structure in Polymer Chemistry. New York: John Wiley \& Sons; 1974. p. 244-305. 